\title{
Are the consumers willing to pay more for local fruits and vegetables? An empirical research on Albanian consumers
}

\author{
ELENA KOKTHI ${ }^{1 *}$ (D), DRITA KRUJA ${ }^{2}$, FATMIR GURI ${ }^{1}$ and \\ OLTJANA ZOTO ${ }^{1}$
}

\author{
${ }^{1}$ Agriculture University of Tirana, Albania \\ ${ }^{2}$ European University of Tirana, Albania
}

\section{CONFERENCE FULL PAPER}

Received: May 5, 2021 • Accepted: July 20, 2021

Published online: August 11, 2021

(C) 2021 The Author(s)

\begin{abstract}
The local food concept is analysed from a supply chain perspective and its positive environmental effects. Revitalised local economies, reduced greenhouse emissions, preservation of farmland and rural lifestyles associated with local products impacts consumer preferences by reflecting a positive attitude toward locally grown products. In addition, the health benefits of local products are more frequently evoked by consumers than those of organic-local products. However, the labelling of such products is used despite consumers and/or producers not being clear about the attributes conferred by the product locality. In this context, this paper aims to clarify the perception of Albanian consumers regarding local fruit and vegetables. The results show that the positive WTP for local food relies on the consumer concern about health and environmental issues. In the case of Albanian consumers, this is driven more by health, taste and environment. Surprisingly, environmental concern exceeds other attributes like price and origin. In this case, environmental issue overlaps health, and it is used as a surrogate indicator for the latter. This is due to the lack of trust in public authorities that fail to assure an efficient quality control process in the agriculture and food sector.
\end{abstract}

\section{KEYWORDS}

local product, consumer preferences, short chains, willingness to pay, contingent evaluation

*Corresponding author. E-mail: ekokthi@ubt.edu.al 


\section{INTRODUCTION}

Scholars analyse local products from a different point of view, i.e., as products used in the short supply chain, their impact on economic development, environmental footprint, and rural development, etc. The increasing interest of consumers in this type of product has further intrigued scholars to analyse such products broadly. It has been found that consumers tend to display a reduced level of insecurity related to food products, such as the impact on health, by electing to buy local food (Adams \& Salois, 2010; Dentoni et al., 2009; Kokthi et al., 2016; Onozaka et al., 2012).

The concept of a local product provides also several applications, such as the Community Supporting Agriculture (CSA), Short Food Supply Chains (SFCs), box scheme, "teikei" system, and roadside market among others. The common feature of all these applications is the direct relationship existing between producer and consumer. This helps in the creation of a loyal link between producer and consumer and produces a short supply chain for products. SFCs are particularly relevant for agricultural products in low/middle-income economies, but not only these. On the one hand, satisfying those consumers who seek a higher level of information about the food products they consume, while on the other, reducing the insecurity of small producers regarding their markets.

The local food concept is a more abstract term compared with that related to organic food (Adams \& Salois, 2010). The local food concept definition depends on consumer perception, cultural heritage, and existing legislation/regulations related to such products. Several authors consider that the concept of local is closely related to cultural values. According to Holt and Amilien (2007), in a study carried out in the UK, local food is usually associated with freshness and low risk. Other authors make a distinction between local and localised products. The local product is only locally-produced, while the localised one has a cultural identity and its characteristics are strongly related to the area of production (Bérard \& Marchenay, 2004a, 2007b). The definition depends upon the links that exist between consumers, producers, and the factors of originality (Bérard and Marchenay, 2004b, 2007a).

Several authors have analysed local food from a supply chain perspective and their socioeconomic and environmental effects (King et al., 2014), identifying a list of impacts that include: a) revitalised local economies, b) reduced greenhouse emissions, c) preservation of farmland and rural lifestyles, and reduced food-based shortage (Lev et al., 2014). These impacts form part of consumer preference and reflect a positive attitude toward these categories of product and in their willingness to pay (WTP). Consumers appreciate several attributes of locally-grown products (Onozaka et al., 2012). found that these attributes can be wide-ranging and include safety, health, social fairness, and sustainability. In related research, the health benefits of local products are more frequently evoked by consumers than those of organic local products.

In low/middle-income countries, local fruit and vegetables are appreciated both by consumers of low income and those earning higher salaries. Poor people buy local food because it is generally cheaper compared with imported products. On the other hand, consumers with higher incomes consider local fruit and vegetables as being healthier, tastier, and having a lower environmental footprint. An understanding of consumer perception of local foods may be used as a guide to small local producers to better design their communication strategy. 
Thus, this paper aims to understand consumer preferences regarding local products in Albania. Willingness to Pay (WTP) estimation, perceptions toward local fruit and vegetables, and the analysis of consumer demographics are the main drivers of this research.

The paper is organised into four sections: the first deals with the rationale of the study. The second section turns its attention to data collection and the applied methodology, while the third illustrates the results. The final section presents the conclusions and a discussion about the results.

\section{MATERIALS AND METHOD}

\section{Sample selection and questionnaire}

The study was conducted in Tirana, the capital of Albania. Tirana is the main market of the country, where nearly one-third of the population of the country lives (more than 800 thousand inhabitants out of 2.9 million in the whole country). The Tirana municipality is comprised of 11 mini municipalities. Two-stage cluster samplings were employed. The first step was to randomly select several mini municipalities: Tirana 1, Tirana 5, Tirana 6, Tirana 10, and Tirana 11. Next, housing units were randomly chosen within each selected mini municipality. Each questionnaire was addressed to the individual responsible for household expenses. As a result, the sample does not reflect the gender distribution of the national population. The process of data collection lasted for two months (February-March 2020) and consisted of a door-to-door interview survey wherein trained interviewers visited the respondent's home and conducted the interview at a scheduled date and time. A total of 434 questionnaires were completed (see Table 1 on sample statistics).

The questionnaire used for this study was composed of two sections: the first one collected the socio-demographic information of respondents such as gender, age, education, income, and household size. The second section pertained to the contingent valuation scenario, asking respondents the extra premium price that they are willing to pay for local fruit and vegetables, explained in the method section.

\section{Method}

The payment card design of Contingent Valuation (CV), similar to that of Hu et al. (2011) was applied. The method of $\mathrm{CV}$ is based on a questionnaire that gathers information in cases where

Table 1. Sample description

\begin{tabular}{lcccc}
\hline Variables & Scale & Description & Mean & Standard deviation \\
\hline Age & $1-6$ & $\begin{array}{c}\text { Age categories } 18-24,25-34,35-44, \\
\text { 45-54, 55-64, 65+ }\end{array}$ & 3.3 & 1.16 \\
Education & $1-3$ & $\begin{array}{c}\text { Education levels (High school; } \\
\text { Bachelor's degree; Master's degree) } \\
\text { Incomes Euro/monthly }\end{array}$ & 1.62 & 0.57 \\
Household size & $1-8$ & $\begin{array}{c}€ 290-435, € 436-580, € 581-725, \\
€ 726-1,084,>€ 1,085)\end{array}$ \\
& $1-6$ & $\begin{array}{c}\text { Number of persons living in the } \\
\text { household }(1-2,3,4,5,6,7)\end{array}$ & 3.6 & 1.19 \\
\hline
\end{tabular}


Table 2. Description of attributes and attitudes

\begin{tabular}{|c|c|c|c|}
\hline \multicolumn{2}{|c|}{$\begin{array}{l}\text { Please rank your level of agreement with of the following statements } \\
1=\text { Strongly disagree, } 5=\text { Strongly agree }\end{array}$} & \multirow{2}{*}{$\frac{\text { Mean }}{4.2}$} & \multirow{2}{*}{$\frac{\mathrm{Sd}}{1.1}$} \\
\hline Environment & $\begin{array}{c}\text { A local product is produced by practices respecting the } \\
\text { environment }\end{array}$ & & \\
\hline Healthy products & A local product is a healthy food & 4.8 & 0.4 \\
\hline Good Taste & $\begin{array}{l}\text { A local product has a better taste compared to a non-local } \\
\text { product }\end{array}$ & 4.6 & 0.6 \\
\hline Price & $\begin{array}{l}\text { A local product is offered with a lower price compared to } \\
\text { non-local }\end{array}$ & 3.8 & 1 \\
\hline Origin & A local product is produced in specific origin & 3.7 & 1.3 \\
\hline Convenience & A local product is more convenient & 3.4 & 1.2 \\
\hline
\end{tabular}

the real market for the product does not exist (Portney, 1994). It is considered to be a declarative method because consumer declarations are analysed, rather than data from real situations. Misra et al. (1991) used the CV method to identify the WTP of consumers for reduced pesticide levels in fresh vegetables. Halbrendt et al. (1995) also used this method to determine the WTP of consumers for pork that contained a reduced quantity of fat. A later study conducted by Buzby et al. (1998) employed the method to evaluate products with less risky ingredients. So too did Loureiro and Hine (2002), who sought to discover the WTP for local, organic, and genetically modified (GM) products.

The payment card method of $\mathrm{CV}$ is easier to apply with consumers compared to other attribute-based approaches such as choice experiments. The application of this method does not require the estimation of the trade-offs between the attributes. In the present study, respondents were presented with five bids and asked: 'Assuming that $1 \mathrm{~kg}$ of fruit-vegetables is priced at 100 $A L L^{1}$ how much are you willing to pay for $1 \mathrm{~kg}$ of locally grown fruit and vegetables? The payment options provided were: 1) No payment $W T P=0,2) W T P=$ up to $20 \%$, 3) $W T P=20 \%$ to $50 \%$ and 4) $W T P>50 \% .100$ ALL is not the actual price for one $\mathrm{kg}$ of fruit and vegetables in the Albanian markets, it represents an anchor price that helps the consumer in their decision process. The CV scenario is complemented with an additional question worded as follows: How much influence have origin, taste, health benefits and environmental aspects of local fruit and vegetables in the expressed WTP where $1=$ not influenced at all, $5=$ strongly influenced. Further questions regarding attitudes on local attributes were based on the five-point Likert scale. This enabled us to understand the associations made about local products. A definition/explanation is provided for each of the attributes (see Table 2 for the description of the attributes). Finally, the purchase place of fruit and vegetables is asked.

\section{Statistical analysis}

The linkage between WTP and demographic factors is investigated through a multinomial regression. Multinomial logistic regression (MLR) is useful to classify subjects based on the values of a set of predictor variables. It is a classification method that generalises logistic

\footnotetext{
${ }^{1}$ Albanian currency $1 \mathrm{ALL}=0,0082$ EUR.
} 
regression to multiclass problems, i.e., with more than two possible discrete outcomes (Green and Kern, 2012). That is, it is a model used to predict the probabilities of the different possible outcomes of a categorically distributed dependent variable, given a set of independent variables that may be binary-valued, categorically-valued, etc.). The model tested for this purpose is as follows:

$$
\begin{aligned}
\mathrm{WTP}= & \beta_{0}+\beta_{1} \text { Age }+\beta_{2} \text { Edu }+\beta_{3} \text { Education }+\beta_{4} \text { Income }+\beta_{5} \text { Householdsize }+\beta_{6} \text { origin } \\
& +\beta_{7} \text { taste }+\beta_{8} \text { healthy }+\beta_{9} \text { environment }+\varepsilon
\end{aligned}
$$

The main indicators when dealing with an MLR procedure include a goodness-of-fit test through chi-square statistics, Pearson and deviance goodness-of-fit statistics, a likelihood ratio test, and the coefficient of determination Nagelkerke's $R^{2}$ (Nagelkerke, 1991). These indicators show whether the model fits the data better than a null model. In addition, the Wilcoxon signedrank test is used to compare the attributes and the importance score expressed by the respondent. This statistical technique is the analogue of paired $t$-test for non-normally distributed data.

\section{RESULTS}

Consumers who buy local products most appreciate the fact that local products are healthier $(A$ local product is a healthy food, mean score $=4,8)$. The findings are in line with those of other scholars showing that the consumer identifies local products as being healthier (Dentoni et al., 2009; Onozaka et al., 2012). Another appreciated attribute relates to taste. According to the respondents, local products taste better. Also, consumers have higher expectations in terms of quality and taste, and assume local to mean healthier (Kokthi \& Kruja, 2016, Kokthi et al., 2016). This result is also due to the perception that local products are misunderstood as having been generated through primitive agriculture. Primitive agriculture, from the consumer perspective, is assumed to be healthier since farmers do not use external inputs within their production system. One unexpected finding of our analysis is that Albanian consumers consider the environmental footprint of the product to be a more important attribute than the place of production. According to a Eurobarometer survey from April 2019, ${ }^{2}$ the most important factors for Europeans when buying food are origin (53\%), price (51\%), food safety (50\%) and taste (49\%). This new result with Albanian consumers should be further analysed to understand if consumer concern for the environment is linked with the environmental sustainability of production or the amount of pesticides and other residuals within the final product. It has previously been concluded by Kokthi et al. (2016) that pesticide-free products are ranked among the top attributes preferred by Albanian consumers due to the negative impact on health rather than for environmental concern. Thus, the environmental attribute might be used by the consumer as a surrogate indicator to the health attribute.

Regarding purchase place, nearly $50 \%$ of the consumers interviewed preferred to buy directly from farmers at roadside stands, $20 \%$ at specialised fruit and vegetable shops, and the remainder (30\%) in supermarkets. The last group considered fruit and vegetables as other food products so, for them, buying these in a supermarket was less costly in terms of time.

${ }^{2}$ https://ec.europa.eu/clima/sites/clima/files/support/docs/report_2019_en.pdf. 


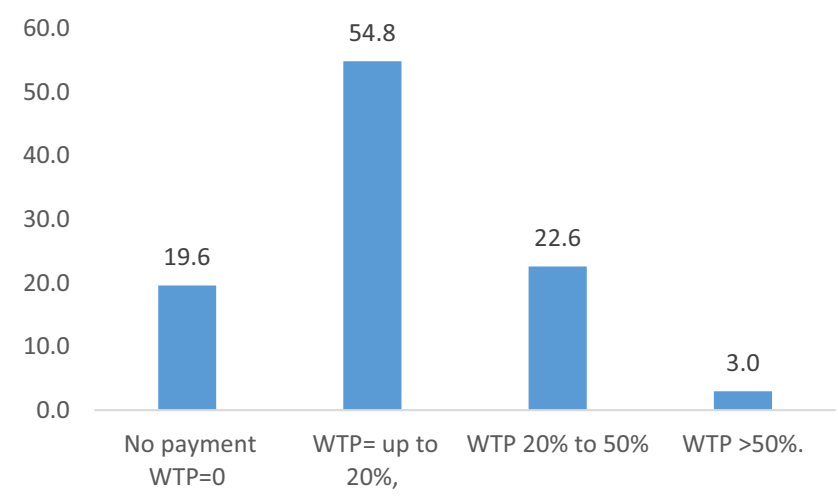

Fig. 1. WTP for local products. Source: author's elaboration

One of the objectives of the paper is also to identify the extra WTP of Albanian consumers for local products. The majority of consumers ready to pay more for local products (54.8\%) showed an extra willingness to pay up to $20 \%$ more. Only a limited share of those interviewed (3\%) was willing to pay $50 \%$ more for local products, with the remainder $(22.8 \%)$ showing a willingness to pay from 20 to $50 \%$ more (see Fig. 1).

Paired comparisons of the environment attribute (a local product is produced by practices respecting the environment) with that of taste (a local product has a better taste compared to a non-local product), through the Wilcoxon signed rank mean ${ }^{3}$ show that consumers gave higher importance to taste than environmental characteristics $\left(Z=-8.038^{* * *}\right)$. The pair comparison between price and environment shows that consumers give higher importance to environment attributes than price when considering local products $\left(Z=-5.452^{* * *}\right)$. These results show that the consumer may be open to other labels, such as environmentally-friendly when considering local products. Other pair comparisons, such as convenience-environment $\left(Z=-6.510^{* * *}\right)$ and origin-environment $\left(Z=-6.454^{* * *}\right)$ show that these attributes are also less preferable compared with the environmental one.

\section{Results of multinomial logit model}

Since the significance level of this test is less than 0.05 (Chi-Square $=398,904, P$-value 0.000 ), we can conclude that this model is outperforming the null. In this model, Nagelkerke's $\mathrm{R}^{2}$ is about 0.68 , showing a good proportion of variance in WTP associated with the independent variables computed in the model. The null hypothesis is that all parameter effects are 0 . Among all the effects tested in the model, only education showed no significant effect (see Table 3 ).

When comparing WTP up to $20 \%$ with WTP $=0$, households with two children were less likely to pay up to $20 \%$ compared to those with three children. High-income earners were more likely to pay this premium than not. Those who judge origin as important while buying local

${ }^{3} P<0.10^{*}$ significant at $P<0.05 ;{ }^{* *}$ significant at $P<0.01 ;{ }^{* * *}$, not significant $=n s$. 
Table 3. Results of the multinomial logistic regression

\begin{tabular}{lcc}
\hline Variables & Chi-Square & $\mathrm{P}$ (value) \\
\hline Education & 6,045 & 0.418 \\
Age & 69,918 & 0.000 \\
Incomes & 130,792 & 0.000 \\
House hold size & 44,999 & 0.000 \\
Origin & 29,262 & 0.004 \\
Taste & 25,766 & 0.002 \\
Healthy & 27,218 & 0.001 \\
Environment & 22,999 & 0.028 \\
\hline
\end{tabular}

were less likely to pay this premium. These results are explained by the fact that origin is not important or else it overlaps local since local identifies the producer's origin. The healthy attribute did not show any significant effect in WTP for a local product even though it is scored higher by the respondents (mean $=4.8$ ). Those who judge taste as neutral regarding local products were less likely to pay up to $20 \%$ than not. Younger people were less likely to pay this premium compared with older consumers. While considering WTP of 20-50\%, the origin and environment attributes linked to local offered an interesting result: people judging origin as not being important were 48 times more likely to pay that premium compared to those who rank it as very important. Regarding the environment attribute, consumers who judge the environment to be important were seven times more likely to pay that premium compared with those who rank it as very important. Income also shows a significant effect, with high-income earners more likely to pay this premium.

\section{DISCUSSION AND CONCLUSIONS}

Consumers who buy local products most appreciate the fact that local products are healthier. However, health attribute did not show a significant effect in the WTP estimations. The result might be linked to the preferences evaluation instrument. The findings are in line with those of other scholars showing that the consumer identifies local products as being healthier (Dentoni et al., 2009; Nurse et al., 2012). Another appreciated attribute relates to taste. According to the respondents, local products taste better than the same product originating elsewhere. As a result, consumers have higher expectations in terms of quality and taste and assume local to mean healthier (Kokthi and Kruja, 2016; Kokthi et al., 2016). This result is also due to the perception that local products are misunderstood as having been generated through primitive agriculture. Primitive agriculture, from the consumer perspective, is assumed to be healthier since farmers do not use external inputs within their production system. One unexpected finding of our analysis is that Albanian consumers consider the environmental footprint of the product to be a more important attribute than the origin of production. Other similar studies (Holt and Amilien, 2007) find that consumers in countries in southern Europe consider origin (localised food systems) to be more important than the environmental footprint of the products they buy. This new result should be further analysed to understand if consumer concern for the environment is linked with the environmental sustainability of production or the amount of 
pesticides and other residuals within the final product. It has previously been concluded by Kokthi et al. (2016) that pesticide-free products are ranked among the top attributes preferred by the Albanian consumer due to their impact on health and are not linked to the environmental concern.

The identification of the positive WTP of Albanian consumers for local fruit and vegetables is only the first step that must be taken to create a sustainable long-lasting relationship between consumers and small producers. Examples of commercialisation schemes (baskets of products or fair trade, etc.) can be used as models to be applied in the Albanian case.

The results of this paper show that the majority of Albanian consumers (80\%) express an extra WTP for local products. Local food is considered to be healthier (mean score 4.8). This explanatory analysis supports the public policy strategy to encourage local products, but further and more detailed analyses are needed to better shape public support and private marketing strategies. Further research will provide more information.

The formalisation of local product schemes will, on the one hand, offer farmers better use of agricultural economic resources, while on the other, reinforce the positive perception and WTP of consumers to such products.

\section{REFERENCES}

Adams, D.C. and Salois, M.J. (2010). Local versus organic: a turn in consumer preferences and willingness to pay. Renewable Agriculture and Food Systems, 25(4): 1-11.

Bérard, L. and Marchenay, P. (2004a). Les produits de terroir; entre cultures et Règlements (CNRS).

Bérard, L. and Marchenay, P. (2004b). Protéger sans appauvrir. In Les Produits De Terroir Entre Cultures Et Réglements, Vol. 1. CNRS, pp. 45-77.

Bérard, L. and Marchenay, P. (2007a). Localized products in France: definition, protection and value adding. Antropology of Food, S2.

Bérard, L. and Marchenay, P. (2007b). Localized products in France: definition, protection and valueadding. Anthropology of Food, S2. https://aof.revues.org/415.

Buzby, J.C., Fox, J.A., Ready, R.C., and Crutchfield, S.R. (1998). Measuring consumer benefits of food safety risk reductions. Journal of Agricultural and Applied Economics, 30(1): 69-82.

Dentoni, D., Tonsor, G.T., Calantone, R.J., Peterson, H.C., Dentoni, D., Tonsor, G.T., Calantone, R.J., and Peterson, H.C. (2009). The direct and indirect effects of 'locally grown' on consumers' attitudes towards agri-food products. https://doi.org/10.22004/AG.ECON.59252.

Green, D.P., and Kern, H.L. (2012). Modeling heterogeneous treatment effects in survey experiments with Bayesian additive regression trees. Public Opinion Quarterly, 76(3): 491-511. https://doi.org/10.1093/ $\mathrm{poq} / \mathrm{nfs} 036$.

Halbrendt, C.K., Sterling, L., Snider, S., and Santoro, G. (1995). Contingent valuation of consumers'willingness to purchase pork with lower saturated fat (No. 1295-2016-102408).

Holt, G. and Amilien, V. (2007). Introduction: from local food to localised food. Anthropology of Food, S2. https://aof.revues.org/405.

Hu, W., Woods, T.A., Bastin, S., Cox, L.J., You, W., Hu, W., Woods, T.A., Bastin, S., Cox, L.J., and You, W. (2011). Assessing consumer willingness to pay for value-added blueberry products using a payment card survey. https://doi.org/10.22004/AG.ECON.104617. 
King, R.P., Hand, M.S., and Gomez, M.I. (2014). Growing Local: case studies on local food supply chains. Lincoln and London: University of Nebraska Press.

Kokthi, E., and Kruja, D. (2016). Consumer expectations for geographical origin: eliciting willingness to pay (WTP) using the Disconfirmation of Expectation Theory (EDT). Journal of Food Product Marketing, 23(8): 873-889. https://doi.org/10.1080/10454446.2017.1244794.

Kokthi, E., Limón, M.G., and Bermúdez, I.V. (2016). Origin or food safety attributes? Analyzing consumer preferences using Likert scale. Empiric evidences from Albania". New Medit, 14(4): 50-57.

Lev, L., Hand, M.S., and DiGiacomo, G. (2014). What does local deliver. Growing local: case studies on local food supply chains, 291-312.

Loureiro, M.L., and Hine, S. (2002). Discovering niche markets: A comparison of consumer willingness to pay for local (Colorado grown), organic, and GMO-free products. Journal of Agricultural and Applied Economics, 34(3): 447-487. https://doi.org/10.1017/S1074070800009251.

Misra, S.K., Huang, C.L., and Ott, S.L. (1991). Consumer willingness to pay for pesticide-free fresh produce. Western Journal of Agricultural Economics: 218-227.

Nagelkerke, N.J.D. (1991). A note on a general definition of the coefficient of determination. Biometrica, 78(3): 691-692.

Nurse Rainbolt, G., Onozaka, Y., and McFadden, D.T. (2012). Consumer motivations and buying behavior: The case of the local food system movement. Journal of Food Products Marketing, 18(5): 385-396.

Onozaka, Y., Nurse, G., and McFadden, D.T. (2012). Local food consumer: how motivations and perceptions translate to buying behavior. Agricultural \& Applied Economics Association.

Portney, P.R. (1994). The contingent valuation debate: why economists should care. Journal of Economic Perspectives, 8(4): 3-17. https://doi.org/10.1257/jep.8.4.3.

Open Access. This is an open-access article distributed under the terms of the Creative Commons Attribution-NonCommercial 4.0 International License (https://creativecommons.org/licenses/by-nc/4.0/), which permits unrestricted use, distribution, and reproduction in any medium for non-commercial purposes, provided the original author and source are credited, a link to the CC License is provided, and changes - if any - are indicated. 